Cambridge University Press

978-0-521-84593-9 - Social Comparison and Social Psychology

Edited by Serge Guimond

Excerpt

More Information

\title{
Introduction: social comparison processes and levels of analysis
}

\author{
Serge Guimond
}

"I do not know how far I differ from other people. That is another memoir writer's difficulty. Yet to describe oneself truly one must have some standard of comparison; was I clever, stupid, good looking, ugly, passionate, cold - ? Owing partly to the fact that I was never at school, never competed in any way with children of my own age, I have never been able to compare my gifts and defects with other people's"

(Virginia Woolf, A sketch of the past, autobiographical writings of 1939)

Fifty years ago, Festinger (1954) published a Theory of social comparison processes. Today, thirty-five social and cognitive psychologists who share a common interest in comparison processes combined their efforts to make this new book on the same topic a reality. Few theories in social psychology have stood the test of time as successfully as the theory of social comparison. Even today, major theoretical and empirical papers on social comparison processes are being published in the best scientific journals (for example, Buunk and Ybema, 2003; Markman and McMullen, 2003; Mugny, Butera, Quiamzade, Dragulescu and Tomei, 2003; Mussweiler, 2003; Spears, Gordijn, Dijksterhuis and Stapel, 2004; Stapel and Suls, 2004 and many others). How can one explain the tremendous amount of research that continues to investigate the psychological role of social comparison? What makes social comparison so important? These questions will be answered in the following chapters.

However, this book is not "only" about social comparison. It is also about social psychology. Social psychology is devoted to understanding and explaining the behavior of individuals. Social psychologists are interested in cognition, how people think and behave. But what makes social psychology a distinctive scientific discipline is its concern with how individual behavior and cognition are shaped by the social context (Monteil, 1998; Monteil and Huguet, 1999). Human beings do not live as isolated individuals. The laboratory situation of a sole individual working on a cognitive task is far from the social reality of individuals constantly interacting with one another at home, at school, at work or at play. Thus, social psychology deals with how we think, feel and behave by 
Cambridge University Press

978-0-521-84593-9 - Social Comparison and Social Psychology

Edited by Serge Guimond

Excerpt

More Information

taking into account the influence of the social environment in which we live. The process of social comparison turned out to be extremely useful in this venture (Turner, Oakes, Haslam, and McGarty, 1994). Indeed, this uniquely social-psychological process arises precisely because we are constantly surrounded by the physical, symbolic or imaginary presence of others. As a result, we can relate to others, we can psychologically compare ourselves to others. Writing in 1939, Virginia Woolf understood amazingly well the power of social comparison, although at that time very little research had been conducted on the topic. There is now a strong body of evidence showing that social comparison processes shape the way we think, feel, and react. The mere fact that we compare ourselves to $\mathrm{X}$ rather than to $\mathrm{Y}$ has the power to transform our thinking, our emotions, and our behaviour. Thus, a first major reason for the persistent importance of social comparison in social psychology is that it allows for a better explanation of social behaviors and provides invaluable insights into the complexities of human social interactions.

Another reason for the striking and continuing influence of social comparison processes in social psychology may be found in the work of Jerry Suls. In addition to several other related publications, three major books on social comparison were edited by Jerry Suls and colleagues, in 1977 (Suls and Miller), in 1991 (Suls and Wills), and in 2000 (Suls and Wheeler). In every instance, the work represented a substantial contribution to theory and research on social comparison. The major influence of these books undoubtedly helps explain the sustaining interest for social comparison in social psychology. Each time, however, this work was also largely focused on social comparisons occurring at the individual level of analysis, not at the group level.

In a paper published in French, Tajfel (1972) argued that it might be useful to think about social comparison occurring not only between individuals but also between groups. These ideas were published in a more expanded version in English in 1974 and formed the basis of one of the most influential theories in social psychology, now known as Social Identity Theory (Tajfel and Turner, 1986). Around that time, Lemaine (1974) was also showing how social comparison can lead to differentiation and the creation of new dimensions of comparison in a search for originality. A year later, an important theoretical paper by Turner (1975) was entitled: "Social comparison and social identity: some prospects for intergroup behaviour." This work, as shown by the title, was devoted to an elaborate discussion of social comparison processes. Yet, even superficial references to Tajfel, Lemaine, Turner, or the topic of intergroup social comparisons cannot be found in Suls and Miller (1977). One has to read eighteen chapters of the Handbook of social comparison (Suls and 
Cambridge University Press

978-0-521-84593-9 - Social Comparison and Social Psychology

Edited by Serge Guimond

Excerpt

More Information

Wheeler, 2000) before coming to Part IV of the handbook, entitled "Applications," to find, in Chapter 19 by Hogg, an analysis of the relations between intergroup social comparisons and social identity. This does not reflect the simple fact that social comparison theory and research in and of themselves have nothing to do with social groups. To the contrary, Forsyth (2000) points out that "social comparison theory is as much a theory about group dynamics as it is a theory about individual's perceptions of their opinions and abilities." (p. 98)

If we examine research dealing with Social Identity Theory, or the related work on the more recent Self-Categorization Theory, a similar state of affairs can be found. Oakes, Haslam, and Turner (1994) do not consider in any substantial manner traditional social comparison research even though their theoretical perspectives highlight the importance of comparative context. Ellemers, Spears, and Doosje's book (1999) entitled Social identity generally confirms this trend. Indeed, Hogg (2000) concluded his chapter by noting that: "Although the cornerstone of social identity theory is the comparative relations that exist between groups and the comparative nature of the social categorization process that underpins social identity phenomena, there is remarkably little systematic attention paid by social identity theorists to social comparison theory." (p. 415) Overall, it seems fair to state that within social psychology, two major traditions of research both dealing with the psychology of social comparison, albeit each in distinctive ways, have ignored each other.

However, there are some significant exceptions to this general trend. Research by Brewer and Weber (1994), Redersdorff and Martinot (2003), Schmitt, Silvia, and Branscombe (2000), and Taylor, Moghaddam, and Bellerose (1989) has endeavored to integrate social comparison processes as they occur both at the individual level and at the group level of analysis. This empirical work strongly confirms one assumption of the present volume: each tradition of research has something of importance to contribute to the other. The nature of our comparative activity, and its role in social life, may be better understood by sharing insights. It is, in part, to address this theoretical gap that the present book was produced. At the intersection of a concern for both the individual person and the social group, theories in social psychology can emphasize one level of analysis (i.e., the individual level) or another (i.e., the group level). One long-term goal is to combine and integrate these various levels of explanation into a better and more thorough theoretical account of human behavior (Doise, 1986). With this goal in mind, the present book is unique in bringing together leading researchers and theorists, many of whom think about social comparison mainly from 
Cambridge University Press

978-0-521-84593-9 - Social Comparison and Social Psychology

Edited by Serge Guimond

Excerpt

More Information

the individual level of analysis whereas others consider primarily the group level of analysis. As such, this work represents the first concerted attempt at fostering the integration of research on social comparison processes occurring at different levels of analysis.

\section{Structure and content: overview of present work}

This book is structured in three parts. Part One deals with social comparison within and between individuals. Part Two is dedicated to social comparison within and between groups, and Part Three examines social comparison processes at the cultural level of analysis. Together, all three sections of this book are necessary to grasp the insights that looking at social comparison processes from different levels of analysis has to offer.

\section{Part One. Cognition}

The four chapters in the first part are devoted to theory and research relevant to comparative processes occurring within and between individuals. In Chapter 1, Buunk and Gibbons present an overview of their program of research on the cognitive and affective impact of upward and downward social comparisons. They approach this topic by considering that whereas everyone will engage in social comparisons from time to time, some people are likely to be more concerned than others by social comparison. The scale of Social Comparison Orientation was developed to measure this varying degree of concern. As very few attempts have been made to study individual differences in social comparison (Wheeler, 2000), the use of this scale by Buunk and Gibbons, in a large variety of contexts and with a wide range of people, to study the impact of social comparison information provides the basis for a refreshing new look at key issues that have dominated traditional social comparison theory and research.

In Chapter 2, Mussweiler, Rüter, and Epstude also deal with key issues emanating directly from Festinger (1954) but from a social cognition perspective. There is no doubt that the social cognition movement has been a driving force behind the theoretical and methodological advances over the last twenty years. It paved the way for a better understanding of the ways in which basic cognitive processes such as memory, attention, and categorization, enter into the construction of social thinking. It led to important innovations in the measurement of traditional psychological concepts such as attitudes, self-esteem, and stereotypes. It raised new issues about automaticity, unconscious cognitions, and the extent to which our behavior is under a certain amount of cognitive control. 
Cambridge University Press

978-0-521-84593-9 - Social Comparison and Social Psychology

Edited by Serge Guimond

Excerpt

More Information

It also brought a renewed concern with the extent to which cognitive activity can be impacted by contextual variables. The work of Mussweiler and colleagues reflects these important developments and not only suggests how they may be fruitfully integrated within social comparison theory and research, but also provides strong empirical support for this new approach.

Continuing this emphasis on cognition, Sanitioso, Conway, and Brunot discuss in Chapter 3 the possible connections between social comparison and autobiographical memory. They present some fascinating evidence of variations in memories as a function of the self and the social context. However, contrary to Mussweiler, Rüter, and Epstude, they attribute a fundamental role to motivation. They consider that much of our social and temporal comparison activities, and their reflections in our autobiographical memories, are driven by the motivation for a positive self-concept. In Chapter 4, Redersdorff and Guimond focus on the issues that Sanitioso, Conway, and Brunot raised at the end of their chapter in relation to temporal-self comparison. They review evidence from studies involving comparison with the past and comparison with the future, using social comparison theory and relative deprivation theory as conceptual frameworks, and note emerging trends that are found when the temporal dimension is considered. They suggest that cognitive factors such as how the past and the future are mentally represented, as well as implicit theories of intelligence, may be as important as motivational factors in order to understand the role of temporal-self comparisons. This is an area where new research is being undertaken and this chapter plays a useful role in trying to specify what is known and what needs to be looked at in the future.

\section{Part Two. Intergroup relations}

Social psychologists have always been interested in cognition (Zajonc, 1980). However, they have also shown a longstanding interest in the psychological aspects of intergroup rivalry and conflict (Sherif and Wilson, 1953). In recent years, the field of intergroup relations took center stage in social psychology largely through the influence of European social psychologists such as Tajfel, Doise, and Moscovici (Moreland, Hogg, and Hains, 1994). From being relatively minor in the 1960s and 1970s, the social psychology of intergroup relations has become one of the most active and influential domains of research within the discipline. Even though social comparison processes between groups were at the very basis of the theoretical explanation of intergroup behavior (Tajfel, 1974; Turner, 1975), this work has not been considered as part of the typical research 
Cambridge University Press

978-0-521-84593-9 - Social Comparison and Social Psychology

Edited by Serge Guimond

Excerpt

More Information

on social comparison processes. In an attempt to foster integrative thinking in this area, the six chapters in Part Two are devoted to theory and research on social comparison within and between groups. The issues raised in these chapters have clear implications for any theory that uses the concept of social comparison. In Chapter 5, Hanna Zagefka and Rupert Brown systematically assess, in a series of ten studies, the factors that have been hypothesized as determinants of social comparison choices in intergroup relations. Their findings are extremely informative in terms of the frequency with which people engage in various types of social comparison in naturalistic settings, and also about the reasons why people do so. As the results are quite consistent from one study to the next, they offer a solid contribution to the literature on social comparison.

The remaining chapters in Part Two are mainly concerned with the effects of social comparison, which represent, with the topic of comparison choices, the defining issues of social comparison research. In Chapter 6, Martinot and Redersdorff present an overview of their experimental research on the effects of ingroup versus outgroup comparisons on selfesteem. The issue of self-esteem is central to both individual-level research and intergroup research on social comparison (see Crocker and Major, 1989; Long and Spears, 1997). One of the main points to emerge from the research of Martinot and Redersdorff is that the effects of social comparison on self-esteem vary in systematic and predictable ways as a function of the level of analysis. In Chapter 7, Garcia, Branscombe, Desmarais, and Gee look at similar issues but in a naturalistic setting. They develop the theoretical implications of Self-Categorization Theory (Turner, Hogg, Oakes, Reicher, and Wetherell, 1987) for an understanding of women and men's attitudes toward gender-based redistributive policies in employment settings. Their findings suggest that these social policies may have some unsuspected effects among those who have experienced them, effects which can be predicted on the basis of the role of intra versus intergroup social comparisons. In Chapter 8, Yzerbyt, Dumont, Mathieu, Gordijn, and Wigboldus argue for the role of social comparison processes in the emergence of group-based emotions. The idea that individuals can experience emotions as group members was developed theoretically by Smith (1993) and led to several studies documenting various facets of these "intergroup emotions." This chapter, however, is the first to reveal the striking impact of contrasting social comparisons on group-based emotions, and to specify the ways in which these comparisons can generate distinctly different emotions.

In Chapter 9, Dambrun, Guimond, and Taylor discuss recent research related to the concept of relative gratification. As Pettigrew (2002) noted: "relative deprivation has been studied for half a century but not its 
Cambridge University Press

978-0-521-84593-9 - Social Comparison and Social Psychology

Edited by Serge Guimond

Excerpt

More Information

reverse - relative gratification. What are the consequences of making comparisons for yourself and your group that reveal your advantaged position?" (p. 354) The aim of the research discussed by Dambrun and colleagues is precisely to investigate the effects of comparing favorably to others. The results are quite clear: people become more prejudiced against low status targets in these conditions. The chapter explores the role of several variables moderating and/or mediating the effects of relative gratification. In Chapter 10, Dumont, Seron, Yzerbyt, and Postmes examine the personal-group discrimination discrepancy from a social comparison perspective. They show that underlying this phenomenon, which has generated numerous studies, are some striking demonstrations of the ways in which social comparisons at the individual level and social comparisons at the group level are both needed to understand people's behavior. Their research identifies conditions under which people are more likely to engage in self-ingroup contrastive social comparisons, distancing themselves psychologically from their ingroup, and as a result, claim that their ingroup is discriminated against, but not themselves.

\section{Part Three. Culture}

The chapters in Part Three address the cultural level of analysis. Culture is a major construct in social sciences and probably the most recent one to become part of mainstream social psychology. Cross-cultural psychologists have long been arguing that in order to develop truly general principles of human behavior, psychological phenomena need to be studied across cultures and not only within cultures. These arguments were often dismissed as being irrelevant to a "proper" scientific approach. There are now definite signs that this is changing. It is becoming more and more frequent to find, in mainstream journals, studies of similarities and differences between people in various cultures. Books have been written about a cross-cultural social psychology (Moghaddam, Taylor, and Wright, 1993; Smith and Bond, 1999) and leading experimental social psychologists have devoted entire research programs to the study of cultural differences (e.g., Nisbett, 2003). Perhaps even more important, there are now indications that social comparison processes have vital methodological as well as theoretical implications for understanding the role of culture (see Heine, Lehman, Peng, and Greenholtz, 2002). Thus, the third and last part of this book is particularly innovative in providing detailed theoretical and empirical analyses of the link between comparative processes and the study of cultures.

In Chapter 11, Fiske and Cuddy discuss the development of the Stereotype Content Model on the basis of a series of international studies. 
Cambridge University Press

978-0-521-84593-9 - Social Comparison and Social Psychology

Edited by Serge Guimond

Excerpt

More Information

They highlight the role of perceived group status which implies a comparative judgment on a dimension of prestige, social standing, or power. Evidence of pancultural uniformity in stereotype content is found among fourteen nations representing diverse cultures and, presumably, various modes of thinking. This raises the question of whether thinking about relative group status could reflect a potentially universal process of social comparison. In Chapter 12, Lorenzi-Cioldi and Chatard also discuss the role of group status and cultural norms but in an entirely different perspective. On the basis of several studies, they suggest that dominant groups are those who embody the dominant cultural norms, such as the norm of individualism in western societies. This implies that subordinate groups are somewhat at variance with such norms. They draw out the implications of this analysis for the operation of social comparison processes and find support for their thinking in studies of gender groups. As such, this chapter explains why women and men can react quite differently to the same social comparison information.

In Chapter 13, Peter Glick presents a cross-cultural analysis of ambivalent gender ideologies based on data from twenty-five nations. He discusses the relations between cross-gender social comparisons and gender inequality, and argues that cultural ideologies can influence such social comparisons. Using the United Nations' index of "objective" gender inequality across nations, he documents how gender ideologies may not simply result from, but may also contribute to, these inequalities. The cultural dimension of power distance (Hofstede and McCrae, 2004) proved to be one important element in providing support for this analysis. In Chapter 14, Michel Désert and Jacques-Philippe Leyens also look at cultures differing on the dimension of power distance but with data from individual participants in a study of gender stereotypes (Part Two of this study is discussed in Chapter 15). Consistent with previous research, they find that beliefs about the attributes of women and men are widely shared across gender and across cultures. However, they report some intriguing interactions, involving gender and cultures, which suggest that there are definite variations in these stereotypic beliefs as a function of power distance. This leads them to point out a number of difficulties in some current theoretical perspectives, such as System Justification Theory (Jost and Banaji, 1994). Indeed, their discussion highlights that gender stereotypes can fulfill many different functions and serve different purposes for dominant as opposed to subordinate groups, and that the systemjustifying function is only one of them.

The concluding chapter is the result of a collaborative effort on the part of several authors of this book. It discusses the findings of one of the first cross-cultural studies of the effects of social comparison. Using 
Cambridge University Press

978-0-521-84593-9 - Social Comparison and Social Psychology

Edited by Serge Guimond

Excerpt

More Information

the Social Comparison Orientation scale (Gibbons and Buunk, 1999), the chapter reports on cultural variations in the propensity to engage in interpersonal social comparisons. As Suls (1986) argued, "Different eras and different cultures may encourage or discourage comparisons with dissimilar others." (p. 111) Consistent with this claim, we do find some remarkable cultural differences in social comparison orientation. Furthermore, manipulating within and between-gender social comparisons, the study explores the extent to which the effects of these comparisons on self-construal vary across cultures. Overall, the findings provide strong support for the idea that social comparison processes at the individual level and at the group level can be useful to understand cultural similarities and differences. This is one way in which social comparison can be used to link together research on cognition, intergroup relations, and culture.

\section{References}

Brewer, M. B. and Weber, J. G. (1994). Self-evaluation effects of interpersonal versus intergroup social comparison. Fournal of Personality and Social Psychology, 66, 268-275.

Buunk, B. P. and Ybema, J. F. (2003). Feeling bad, but satisfied: The effects of upward and downward comparison upon mood and marital satisfaction. British Fournal of Social Psychology, 42, 613-628.

Crocker, J. and Major, B. (1989). Social stigma and self-esteem: The self protective properties of stigma. Psychological Review, 96, 608-630.

Doise, W. (1986). Levels of explanation in social psychology. Cambridge: Cambridge University Press.

Ellemers, N., Spears, R., and Doosje, B. (eds.) (1999). Social identity. Oxford: Blackwell.

Festinger, L. (1954). A theory of social comparison processes. Human Relations, $7,117-140$.

Forsyth, D. R. (2000). Social comparison and influence in groups. In J. Suls and L. Wheeler (eds.), Handbook of social comparison: Theory and research (pp. 81-104). New York: Kluwer Academic/Plenum Publishers.

Gibbons, F. X. and Buunk, B. P. (1999). Individual differences in social comparison: Development and validation of a measure of social comparison orientation. Fournal of Personality and Social Psychology, 76, 129-142.

Heine, S. J., Lehman, D. R., Peng, K., and Greenholtz, J. (2002). What's wrong with cross-cultural comparisons of subjective likert scales? The referencegroup effect. Fournal of Personality and Social Psychology, 82, 903-918.

Hofstede, G. and McCrae, R.R. (2004). Personality and culture revisited: Linking traits and dimensions of culture. Cross-cultural Research, 38, 52-88.

Hogg, M. A. (2000). Social identity and social comparison. In J. Suls and L. Wheeler (eds.), Handbook of social comparison: Theory and research (pp. 401-422). New York: Kluwer Academic/Plenum Publishers. 
Cambridge University Press

978-0-521-84593-9 - Social Comparison and Social Psychology

Edited by Serge Guimond

Excerpt

More Information

Jost, J. T. and Banaji, M.R. (1994). The role of stereotyping in systemjustification and the production of false consciousness. British fournal of Social Psychology, 33, 1-27.

Lemaine, G. (1974). Social differentiation and social originality. European fournal of Social Psychology, 4, 17-52.

Long, K. and Spears, R. (1997). The self-esteem hypothesis revisited: Differentiation and the disaffected. In R. Spears, P. J. Oakes, N. Ellemers, and S. A. Haslam (eds.), The social psychology of stereotyping and group life (pp. 296-317). Oxford: Blackwell.

Markman, K. D. and McMullen, M.N. (2003). A reflection and evaluation model of comparative thinking. Personality and Social Psychology Review, 7, 244-267.

Moghaddam, F. M., Taylor, D. M., and Wright, S. C. (1993). Social psychology in cross-cultural perspective. New York: W. H. Freeman.

Monteil, J.-M., (1998). Contexte social et performances scolaires: Vers une théorie du feed-back de comparaison sociale. In J.-L. Beauvois, R.-V. Joule, and J.-M. Monteil (eds.), 20 ans de psychologie sociale expérimentale francophone (pp. 151-187). Grenoble: Presses Universitaires de Grenoble.

Monteil, J.-M. and Huguet, P. (1999). Social context and cognitive performance: Towards a social psychology of cognition. London: Psychology Press.

Moreland, R. L., Hogg, M. A., and Hairns, S. C. (1994). Back to the future: Social psychological research on groups. Fournal of Experimental Social Psychology, 30, 527-555.

Mugny, G., Butera, F., Quiamzade, A., Dragulescu, A., and Tomei, A. (2003). Comparaisons sociales des compétences et dynamique d'influence sociale dans les tâches d'aptitudes. L'Année Psychologique, 104, 469-496.

Mussweiler, T. (2003). Comparison processes and social judgment: Mechanisms and consequences. Psychological Review, 110, 472-489.

Nisbett, R. E. (2003). The geography of thought: How Asians and Westerners think differently and why. London: Nicholas Brealey Publishing.

Oakes, P. J., Haslam, S., and Turner, J. C. (1994). Stereotyping and social reality. Malden, MA: Blackwell Publishers.

Pettigrew, T.F. (2002). Summing up: Relative deprivation as a key social psychological concept. In I. Walker and H. J. Smith (eds.), Relative deprivation: Specification, development and integration (pp.351-373). Cambridge: Cambridge University Press.

Redersdorff, S. and Martinot, D. (2003). Impact des comparaisons ascendantes et descendantes sur l'estime de soi: importance de l'identité mise en jeu. L'Année Psychologique, 104, 411-444.

Schmitt, M. T., Silvia, P. J., and Branscombe, N. (2000). The intersection of selfevaluation maintenance and social identity theories: Intragroup judgment in interpersonal and intergroup contexts. Personality and Social Psychology Bulletin, 26, 1598-1606.

Sherif, M. and Wilson, M. O. (eds.) (1953). Group relations at the crossroads. New York: Harper and Brothers.

Smith, E. R. (1993). Social identity and social emotions: Towards new conceptualizations of prejudice. In D. Mackie and D. Hamilton (eds.), Affect, cognition and stereotyping (pp. 297-315). San Diego, CA: Academic Press. 